\title{
Blockchain as a trust layer for more efficient finance market
}

\author{
Dmitriy Golovyonkin ${ }^{1}$, Elena $V$. Karanina ${ }^{1}$, Larisa $V$. Kryuchkova ${ }^{1, *}$, Svetlana $V$. Grin ${ }^{1}$, \\ Julia $V$. Davydova ${ }^{1}$ \\ ${ }^{1}$ Vyatka State University, Finance and Economic security Department, 600000 Kirov, Russia
}

\begin{abstract}
This article covers a variety of topics on blockchain and the impact that digital encryption and social engineering will have on finance society. In modernized mortgage market, exchange would happen naturally, allowing users to benefit from a web of trust, where parties do not need to be in a direct relationship with each other to reap rewards from referrals that originate from multiple parties. Pseudonymity and honesty are properties that blockchains handle natively, and this is a candidate solution to the "transparency" problem in lending and borrowing, which acts as a trust inhibitor at scale for many interactions.
\end{abstract}

\section{Introduction}

The blockchain is the subject notoriously difficult to explain well. There's quite a lot going on in the trust layers space right now.

Blockchain now can bring amazing results to industries as diverse as health care, supply chain management, music rights, and finance.

There are some hopes that blockchain will transform the mortgage landscape [1], and we should see more innovation and consolidation in mortgage service. Many finance industry experts have some concerns about its impact and challenges [2], but it is clear that blockchain will change the principles for storing information at transactional level and for storing account information. It is believed that splitting traditional relationship into these two, web of trust will allow one to optimize the system with respect to scalability and privacy [3]. Common people provide a lot of private information about themselves and especially their relatives, neighbours and colleagues in social networks, and blockchain with the help of booming data mining technics such as logistic models, neural networks, regression, clustering, prediction, outlier detection and visualization could enhance system defence against finance fraud [4].

Technically speaking, a blockchain is a linked list of blocks, and a block is a group of ordered transactions.

The main thing distinguishing a blockchain from a normal database is that there are specific rules about how to put data into the database.

That is, it cannot conflict with some other data that's already in the database (consistent), it's append-only (immutable), and the data itself is locked to an owner

\footnotetext{
*Corresponding author: 1_v_kruchkova@mail.ru
} 
(ownable), it's replicable and available. Finally, everyone agrees on what the state of the things in the database are (canonical) without a central party (decentralized).

The core feature of this technology is decentralization.

The record of transactions or better to say a copy of it lives on every node of the network. New transactions once being added to this record are broadcasted to everyone, so everyone gets the updates. Once something is recorded, it becomes immutable and everyone verifies their own transactions, putting the trust on the whole network.

Decentralization is very attractive because it implies there is no single point of failure. That is, no single authority will be able to take away your asset or change "history" to suit their needs. This immutable audit trail where you don't have to trust anyone is the benefit that everyone who's playing with this technology is looking for.

On the other hand, blockchain is scary for many. If the rules are insufficient to deter bad behaviour, the society is out of luck. Blockchain doesn't serve any government, organization, or finance institution. There is no spirit of the law here. One simply has to deal with malicious or misbehaving actors, possibly for a very long time. And if most of the individuals in the network decide to turn dishonest and cheat the rest of the network, the protocol will fail its purpose.

To pessimists, "blockchain" is really just a way to get rid of the heavy apparatus of government regulation. For instance, China is cracking down on not only cryptocurrencies and its miners, but centralized exchanges as well.

Of course, the core feature of blockchain technology is cryptography and hash functions specifically. There is a distributed ledger that is immutable and extremely difficult to hack.

Technically speaking, hash function describes in terms of input and output - given an output, it is extremely difficult to calculate the input, but given an input and output, it is pretty easy to verify if the input leads to the output.

Special topic to discuss is a cryptocurrency which is the combination of four technologies: blockchain, proof-of-work, cryptography, and peer-to-peer network. But this is out of the scope of this work.

Blockchain technology was not affordable before XXI century. That is why, in order to establish trust between ourselves, we depended on individual third-parties.

Why is blockchain so expensive?

A traditional finance database with client's data only needs to be written to once. A blockchain needs to be written to thousands of times.

A traditional finance database needs to only checks the data once. A blockchain needs to check the data thousands of times.

A traditional finance database needs to transmit the data for storage only once. A blockchain needs to transmit the data thousands of times.

The overhead of transmission, verification and storage is enormous as every single copy of the database must pay them instead of those costs being paid just once in a traditional, a la past century database.

A centralized database is much faster, less expensive, easier to maintain and easier to upgrade than a blockchain.

So why do people keep using the word blockchain with its rising costs as if it's some sort of panacea for all their problems? We've already established that a blockchain is very expensive relative to centralized databases.

So, the only reason one should use a blockchain is to decentralize. Centralized organizational structures of modern finance make finance decisions non-transparent and this adds to the problem of so called "white-collar crime" [5].

Besides rising costs, the real problem with blockchain implication is that some of these projects aren't really innovating. Blockchain is a way to look like you're on the leading edge of technology. 
A lot of bad ideas are being peddled to investors disguised as innovation-when it's really business as usual.

One can take some business idea, write up a proposal, sprinkle the word blockchain here and sell for naive investors. One can also take ordinary business plan and replace every instance of the word blockchain with database. And if it'll still read the same, those businesses are not building decentralized services.

\section{Modern finance and a lack of trust}

From ancient history seller and consumer, borrower and lender trusted the bank to manage their money. Modern money for example is just a framework for keeping the government guarantee instead of gold in place so that more private capital is introduced into the national market.

What is the problem with this?

There are four categories of financial fraud: bank fraud, insurance fraud, securities and commodities fraud, and other related financial fraud [4].

Let us review American mortgage market.

Since the advent of mortgages, there has been mortgage fraud. And the level of mortgage fraud has continued to experience an unprecedented increase over the last century and there are some solid reasons as to why this is so.

The greatest fraud in the history happened in United States in last decade before 2008. To understand it we must go back to 1938 and recall the founding of Federal National Mortgage Association (Fannie Mae) and her siblings a bit later.

The original mortgage market was small and the requirements where rather high like a job history, a salary four times the amount of the monthly mortgage instalment, a $20 \%$ down payment and so on.

The Fannie Mae idea was to buy mortgages that met her standards from initial lenders. These lenders were private investment companies and nationwide commercial banks. Government backed institution would buy them, package and sell them to fearful investors with an implied guarantee that it would pay if the mortgagors didn't.

Diversification allowed Fannie Mae to have the same lending standards but with lower down payment. In these conditions, this kind of accounting fraud was inevitable.

That is how "white-collar" crime began. From the last decade of XX century, loans were packaged by investment banks, in a way that created complex layers of securities that would leave the senior bank officers rich even if the institution itself (the bank) failed.

And it led to 2009 subprime mortgage crisis with its toxic synthetic Mortgage Backed Securities (MBS) and Collateralized Debt Obligations (CDOs).

The contributing factors of the crisis: predatory lending, predatory borrowing and mortgage fraud, unethical practices, unregulated mortgage brokers, off-balance-sheet activity, and the infusion of capital from Asia that provided the fuel for subprime mortgage activity to continue [6].

Let us disaggregate these factors.

1. Borrower fraud

If someone has made no down payment on its property, he stands to lose nothing in case of default. Of course, the bank will repossess his property but he doesn't lose any of his own money when and if this happens.

2. Initial lender fraud

Mortgage lenders in modern history are not investors but commission agents - they don't keep the loan in their own books. They package it as securities and sell it off to investors on the Wall Street. Lenders were practically creating risky loans and passing them off to others, while taking their cut of the profit as a fee. 
Banks for their own part started investing this money into short term projects that could earn them a return high enough to pay back their depositors and make a profit for risking their money.

Nowadays finance institutions continue to make high-value mortgages available to people who cannot afford them. And that people who received loans without verifiable employment do not intend to repay what they borrowed

3. Federal National Mortgage Association fraud

This is classical principle-agent problem. Its managers just want their salaries and have no long-term responsibilities.

All the risk finally was covered by tax payers. It's been 10 years since the U.S. government took control of mortgage giants Fannie Mae and Freddie Mac during the depths of the financial crisis.

This government's backed institutions do not issue mortgages themselves, so they have lack of information about their assets. They buy loans from lenders, wrap them into securities and make guarantees to investors in case borrowers' default. The process frees up cash for lenders to underwrite more mortgages.

4. Rating agencies fraud.

Both rating agencies and investors were confident in the expected return from collateralized securities. They believed that even if some of these loans failed, they would still get the title to the property and sell it in the market at the outstanding value of their loan, if not for a profit. These investments were considered a win-win situation with nothing to lose.

Mortgage fraud is still remaining a controversial issue between brokerage firms, banks, and consumers looking to buy homes. These securities were offered at a very high rate of return for investors which made them very lucrative.

Since these securities are also backed by physical properties, they are considered relatively secure. Every sold house confirms the price of previously sold houses in this neighbourhood. So, there are always motives to add new element to the "chain of untrusted" overpriced physical property.

What are the current methods of fraud?

1. Non-existent employers.

Brokers would love to catch every fraudulent application, but often, they simply don't have the time to investigate questionable applications or double-check applications that appear to be legitimate.

2. Verification of lending.

Regulatory bodies are warning lenders to examine submissions provided by independent and group brokerages more closely. But the appearance of legitimacy and verifiable truth are not the same thing, though. Some American developers pleaded guilty to a scheme in which they falsified closing cost information to swindle money from a lender via wire transfer. Another example, a potential borrower concealed sales incentives to secure private loans from investment bank, stealing almost $\$ 1$ million.

So, the important reason why there is an increase in the level of mortgage fraud is the system's total lack of transparency. This is a problem that blockchain aims to solve.

Blockchain ledger would do a much better job of regulating the lending process, something that governments, banks, regulators, rating agencies and policy makers failed to do in 2008. 


\section{How blockchain can stop rising mortgage fraud}

1. Most modern finance intermediary institutions of centralization compromise themselves. Banks and large finance institutions currently dominate finance environment and they take extra profits from this space.

The point of blockchain is that they remove the need for a centralized authority. They provide trusty, neutral, borderless, and censorship-resistant platforms to exchange value on. If someone is taking a process and shifting the trust to new intermediaries like governments, banks or finance corporations - so called "permissioned blockchains"- it is not innovating at all. He is just a new middleman. Although they could use this technology to make the same centralized processes more efficient.

2. The blockchain solution seems to be the only feasible solution to the excesses of mortgage frauds. A Blockchain based system would have provided far greater analytical transparency and let the investors know what they were signing on to. The publicly shared network would have also allowed the regulators to step in before things collapsed.

Smart contracts between investors and borrowers enabled by blockchain should manage the entire transaction workflow, with ease of access to social networks data and automation replacing the paper-driven pain of the current process.

A smart contract serves as a single platform that integrates all contractual due diligence with the flow of money and is structured in a way to ensure the transaction does not move forward until all contingencies are met. Investors should know precisely the asset quality ratings of the mortgages they purchase. This transparency allows investors to cherry-pick their investments.

3. We have seen the rise of crowd financing in the past decade. Recent technology makes this process proceed in a trusted seamless manner.

The blockchain and related platforms are the key to redesign this relationship with mortgages. Tracking supply chain networks of assets and the circle of income and expenses is very important for the purposes of integrity and transparency. This is particularly useful in the financial securities industry. For example, collateralized securities like those we have in the mortgage industry are loans backed against physical properties.

In order to determine the true value of these securities it is very important to understand the characteristics of the market and the demand for these properties. It would let us monitor the situation better by providing relevant information.

Blockchain protocol allows bankers to make their ledgers publicly accessible, the encryption technology ensures that it can only be accessed by authorized parties. This allows stakeholders to perform real-time analysis and adds trust in the financial strength of other banks.

As a result, the blockchain platform will improve the sharing of data between investors, borrowers and bankers.

The blockchain mortgage should operate in pretty much the same way a regular mortgage does but with a few key differences. It will be governed by smart contracts to enable a trusted peer-to-peer relationship between the homeowner and any investor. So called tokens which represent parts of the modern mortgage will be tradable at any stage, therefore making a once illiquid market, liquid. They will also derive their value from the physical asset they represent, using local and nationwide property land data and house price index data to determine the value of the token.

The homeowner should have the option to buy back the tokens owned by other investors over time, just like somebody would repay a mortgage over several years. This token ownership can be flexible, and renegotiated over time, with the assistance of smart contracts efficiently intermediating this relationship.

Smart contracts technology should improve the ability to assess risk. 
Investors will set their own risk parameters when considering lending for developments and mortgages. Blockchain will offer a wide range of investment projects with different risk reward levels and being backed by real estate. By removing the middleman of the bank and replacing its services with transparency and automation we can give both sides of the project cost savings.

Lower risk means lower interest on mortgage debt and in the long run this will influence housing prices.

Fraud and social network and their relationship are a special topic to research and discuss.

On one hand, the network could encourage people to spread fraud [7] by use of change agents, like principals and employees on Enron company, who invested their personal time and effort recruiting naïve investors, independent brokers actively spread the fraud to their clients; and opinion leaders, investors themselves, unknowingly spread the fraud through their social networks by recruiting their friends and family to invest in Ponzi like scheme.

On the other hand, network could enhance risk assessment.

Today borrower-scoring applications completely disregard his actual network, which contains the relevant people. Many of the problems of debtor assessment could be solved by friend and family's knowledge to improve or decrease his rating. Decentralized financial networks should incentivize referrals more strongly and could allow the formation of an incentive market. Theses incentives mean an increase in the number of network users, the frequency of their scores, and the effectiveness of those assessments. Data mining, artificial intelligence and machine learning combined with ever-growing network information could begin to restore confidence of consumers and investors worldwide. Social media makes that process quick and easy.

Of course, laws and regulations must be enacted quickly to correct the access to this data and address the mortgage fraud once it appears within some community.

In the face of still rising mortgage fraud, brokers stand as the lending industry's first line of defence.

Brokers cannot just look briefly over the information applicants submit. Instead, they should do real research alongside the underwriter to verify everything about the applicant.

This work didn't come easy last century.

There was formal check of the quality of employment communications like professional letterhead, grammatical errors, matching numbers from the employer and submitted by the applicant. Bank data inconsistencies were also under suspicion. Banking documents should match the information from the applicant's income. If bank records indicate that the down payment is a collection of multiple cash deposits, the broker used to treat the application with extra caution. Some applicants faked entire accounts, but brokers can solve that issue with a quick call to the bank to verify the account's existence.

Every fraudulent application found by magnifying glass of data mining applications based on blockchain technologies saves a lender thousands of dollars. If brokers begin to investigate applications more thoroughly, would-be fraudsters will have their work cut out for them. The threat of defaulting house loans potentially leaves a concerning number of home buyers vulnerable, mostly those who've invested in property with down payments valued less than $20 \%$.

So, the main principles of the financial networks are:

1. Integrity - an openly accessible system would have allowed investors and banks to audit the records. This lets them make sure that all the information is accurate with no manipulation.

2. Completeness - the blockchain will use encryption technology and maintain record of every single transaction that has been made on the platform. The completeness of the record is more reliable than records where initial transactions are missing 
3. Online transparency - blockchain records are available for viewing from anywhere around the world. Greater availability allows banks to analyze in real time and allows them to quickly respond to changes in the market.

\section{References}

1. J. Mathis, Journal of Private Equity 20(3) (2017)

2. P. Treleaven, R.G. Brown, D. Yang, Blockchain Technology in Finance 50(9) (2017)

3. W.-T. Tsai, R. Blower, Y. Zhu, L. Yu, IEEE Symposium on Service-Oriented System Engineering (2016)

4. E.W.T. Ngai, Y. Hu., Y.Y. Wong, Y. Chen, X. Sun, Decision Support Systems 50(3) (2011)

5. R. Tillman, H. Pontell, Organizations and Fraud in the savings and loan industry Social Forces 73(4) (1995)

6. G.H. Lander, Barker K., Zabelina M., Williams T.A Subprime, International Advances in Economic Research 15(1) (2009)

7. R. Nash, V. Bouchard, A. Malm, Social Networks 35(4) (2013)

8. A.T. Carswell, D.C. Bachtel, Crime, Law and Social Change 52(4) (2009) 